\title{
Analisis Faktor Pengusaha Kuliner Menggunakan Jasa Iklan Instagram "Jakul Semarang" Sebagai Endorser
}

\author{
Amanda Ayu Dani dan Sentot Suciarto, A. \\ email: sentot.sa@unika.ac.id \\ Program Studi Manajemen, Fakultas Ekonomi dan Bisnis \\ Universitas Katolik Soegijapranata
}

\begin{abstract}
Culinary Businessman uses advertising service like Jakul Semarang Instagram as endorser. Sample chosen for this research were 65 respondents by purposive sampling. Based on factor analysis, it was found that some factors pushing some businessmen in Semarang City to promote at Jakul Semarang included endorser account credibility, endorser characteristic, product picture which liked by follower, and endorser effectiveness. The dominant factor was endorser account credibility. There were four variables in this factor namely number of followers' and likers' credibility, the easily known hashtag, the simplicity of endorser performance, and the number of likers per picture.
\end{abstract}

Keywords: credibility of endorser account, endorser characteristics, endorser effectiveness, instagram follower.

\begin{abstract}
Abstrak
Pengusaha kuliner menggunakan jasa iklan instagram "Jakul Semarang" sebagai endorser. Dipilih sampel untuk penelitian ini berjumlah 65 responden dengan purposive sampling. Berdasarkan analisis faktor didapat beberapa factor yang mendorong para pengusaha di kota Semarang untuk melakukan promosi di Jakul Semarang, yaitu faktor kredibilitas akun endorser, faktor karakteristik endorser, faktor gambar produk yang disukai follower, dan faktor efektivitas endorser. Faktor kredibilitas akun endorser menjadi faktor yang paling dominan dalam mendorong para pengusaha di kota Semarang untuk melakukan promosi di akun instagram Jakul Semarang. Faktor tersebut terdiri dari 4 (empat) variabel, yaitu kepercayaan terhadap jumlah followers dan likers, hashtag yang mudah dikenali, kemudahan kinerja endorser, dan variable jumlah liker di setiap gambar.
\end{abstract}

Kata Kunci: kredibilitas akun endorser, karakteristik endorser, efektifitas endorser, follower instagram. 
JEMAP : Jurnal Ekonomi, Manajemen, Akuntansi dan Perpajakan

ISSN : $\quad$ | Vol. 1 | No. 1 | April 2018

\section{PENDAHULUAN}

\section{Latar Belakang}

Pertumbuhan industri makanan dan minuman termasuk pertumbuhan yang menggembirakan karena bertumbuh positif di atas lima persen per tahun. (www.finance.detik.com dan www.industry.co.id ). Akibat tingkat pertumbuhan yang positif tersebut, banyak resto atau rumah makan kecil yang bermunculan di Semarang seperti cafe atau online kuliner shop yang menandakan Semarang dapat menjadi pasar bagi para pebisnis kuliner. Bagi para pengusaha kuliner lokasi merupakan persoalan yang penting, tetapi saat ini dengan online dapat juga dipasarkan produk-produk kuliner dengan cara pre-order. Pengusaha menggunakan bisnis secara online, dan secara offline. Dalam melakukan promosi online, bisa dilakukan melalui internet dengan berbagai cara seperti, website, media sosial dan lain-lain.

Menurut data Asosiasi Penyelenggara Jasa Internet Indonesia (APJII) yang bekerjasama dengan Pusat Kajian Komunikasi (PUSKAKOM) Universitas Indonesia yang dirilis pada tanggal 14 maret 2015, dilakukan survey kegiatan pengguna internet di Indonesia. Ada 87 persen yang menggunakan jejaring sosial. Sedangkan 69 persen menggunakan internet untuk info searching/browsing. Sebagian pengguna internet, sejumlah 60 persen menggunakan untuk instant messaging. Yang mencari berita terkini ada 60 persen juga. Selain itu ada juga yang memakai internet untuk video streaming 27 persen, untuk email ada 25 persen, ada yang melakukan jual beli online 11 persen, demikian juga game online 11 persen dan hanya 4 persen menggunakan untuk forum online. Dapat disimpulkan bahwa jejaring sosial atau media sosial merupakan kegiatan yang sering dilakukan oleh orang Indonesia, karena media sosial digunakan untuk interaksi terhadap orang lain, berbagi pengalaman, serta melakukan bisnis online, yang bisa memperkuat peluang pasar di Indonesia. Untuk jaman sekarang diharuskan para pebisnis menggunakan sosial media karena memiliki peran penting. 
JEMAP : Jurnal Ekonomi, Manajemen, Akuntansi dan Perpajakan

ISSN : $\quad$ Vol. 1 | No. 1 | April 2018

Media sosial adalah teknologi yang mobile dan berbasis web, yang mendorong interaksi di antara pihak-pihak yang menggunakannya (Rermawan, 2012: 226). Meskipun media sosial banyak ragamnya, tetapi Instagram, Facebook, dan Twitter merupakan beberapa jejaring sosial yang sedang menjadi trend saat ini. Di penelitian ini, media sosial Instagram yang akan diteliti dikarenakan media sosial saat ini yang paling trend adalah Instagram. Instagram diluncurkan pada bulan Oktober 2010, telah memiliki 300 juta pengguna pada tahun 2014, melebihi twitter. Strategi pemasaran via Instagram dapat mengembangkan usaha menjadi lebih baik. Bisnis online juga sudah banyak beralih ke Instagram karena kemudahan mereka mengupload produk, memberi deskripsi produk dengan jelas, serta dapat melakukan promosi atau media periklanan secara online.

Para pebisnis membidik target usia 18-25 tahun. Konsumen muda yang akan diteliti ini merupakan mayoritas pengguna internet menurut Asosiasi Penyelenggara Jasa Internet Indonesia (APJII). Berikut adalah data pengguna internet di Indonesia berdasarkan usia. Usia 18-25 tahun sejumlah 49 persen; usia 26-35 tahun sejumlah 33,8 persen; usia 26-35 tahun sejumlah 33,8 persen; 36-45 tahun sejumlah 14,6 persen; dan 56-65 tahun sejumlah 0,2 persen. (Sumber: "Data PUSKAKOM dan APJII 2015")

Instagram tidak hanya media sosial untuk berbagi foto dan video, tetapi juga media sosial untuk melakukan penjualan atau melakukan bisnis secara online, maupun promosi secara online. Berdasarkan survey yang dilakukan oleh Jakpat terhadap 530 responden, sebesar 53\% responden mengatakan bahwa kegiatan yang mereka lakukan adalah mencari akun online shop, dan responden yang mencari akun kuliner sebesar 38,4\%. Keuntungan dari belanja online adalah bisa dilakukan dimana saja dan bisa sambil duduk dirumah dengan santai di depan handphone atau tab atau komputer. Dalam melakukan penjualan atau pemasaran seperti promosi tidak mengeluarkan biaya yang terlalu besar seperti pada belanja offline. 
JEMAP : Jurnal Ekonomi, Manajemen, Akuntansi dan Perpajakan

ISSN : $\quad$ | Vol. 1 | No. 1 | April 2018

Periklanan online yang dilakukan di media sosial menggunakan daya tarik peran pendukung (endorser), dimana endoser sendiri merupakan pendukung iklan atau juga yang dikenal sebagai bintang iklan yang mendukung produk iklan tertentu. Endorser terbagi dalam dua jenis yaitu Typical Person Endorser dan Celebrity Endorser. Pengertian dari Typical Person endorser adalah penggunaan beberapa orang yang tidak berasal dari kalangan selebritis untuk menyampaikan pesan mengenai sebuah produk dan Celebrity Endorser adalah penggunaan orang yang telah terkenal yang dapat mempengaruhi orang lain karena prestasi yang dimilikinya (Shimp, 2004). Daya tarik iklan melalui media internet ini ternyata cukup efektif untuk menarik para konsumen atau calon konsumen.

Dalam penelitian ini, diteliti media sosial melalui Instagram dan dipilih celebrity atau foodstagram endorser yaitu "JakulSemarang" yang merupakan ahli dalam bidang mempromosikan kuliner yang ada di Semarang. Jakul Semarang merupakan akun foodstagram yang terpercaya di Semarang. Akun tersebut dipercaya karena jumlah follower nya yang banyak (105.000 orang) dan menyakinkan. Umur akun endorser sudah sejak 11 April tahun 2014. Jumlah like setiap gambar yang diupload rata-rata dari 900 hingga 2000 keatas. Banyak respon dari para pengusaha kuliner mengatakan bahwa "Jakul Semarang" memiliki pasar konsumen yang tepat dan mereka mendapatkan promosi yang efektif atau efektivitas promosi dari endorser tersebut bagus.

Sebelum melakukan penelitian lebih lanjut, dilakukan pra survey. Pra survei ini dilakukan terhadap pengusaha kuliner yang melakukan promosi iklan di akun endorser "Jakul Semarang". Responden dalam survei awal ini adalah para pebisnis yang pernah melakukan promosi di "Jakul Semarang". Survei awal dengan menggunakan kuesioner dilakukan pada tanggal 23-26 Juni 2016 kepada 7 responden, lalu dilanjut melakukan survey ulang pada tanggal 2 September 2016 kepada 13 responden. Didapatkan bahwa paling banyak alasan pebisnis kuliner melakukan promosi online di dinstagram karena jumlah followers akun endorser (13 responden). Yang lainnya karena kredibilitas endorser, kinerja endorser, daya Tarik positif endorser, efektifitas, dan 
kepercayaan terhadap followers (rata-rata 7 responden). Berdasarkan alasan di atas, maka dipilih judul artikel "Analisis faktor pengusaha kuliner menggunakan jasa iklan instagram "Jakul Semarang" sebagai endorser.

\section{Rumusan Masalah}

Berdasarkan latar belakang yang sudah diuraikan, maka dapat dirumuskan rumusan masalah pada penelitian ini, yaitu faktor apa saja yang mendukung para pengusaha ingin mempromosikan produknya melalui endorser instagram di "Jakul Semarang"? Faktor apa yang paling mendorong para pengusaha untuk mempromosikan produknya melalui endorser instagram di "Jakul Semarang"?

\section{Tujuan dan Manfaat Penelitian}

Tujuan penelitian ini adalah untuk mengetahui alasan apa saja yang mendukung para pengusaha ingin mempromosikan produknya melalui endorser instagram di "jakul semarang"; untuk mengetahui alasan apa yang paling dominan mendukung para pengusaha ingin mempromosikan produknya melalui endorser instagram di "jakul semarang". Manfaat penelitian ini bagi endorser Jakul Semarang diharapkan mampu meningkatkan dan mempertahankan layanan jasa dengan memperhatikan faktor-faktor yang ada dalam penelitian ini dan menjadi informasi bagi pebisnis kuliner online. Sedangkan bagi peneliti lain, penelitian ini bermanfaat menambah pustaka terkait periklanan dalam bidang pemasaran online.

\section{LANDASAN TEORI}

\section{Komunikasi Pemasaran}

Pengertian dari komunikasi adalah proses menyampaikan suatu pesan dari sumber pemikiran, perencanaan dan pemahaman yang disampaikan oleh individu atau suatu organisasi kepada seseorang atau organisasi yang memberikan efek terhadap penerima setelah menerima pesan tersebut (Rermawan, 2012). Sedangkan pengertian pemasaran adalah fungsi organisasi dan serangkaian proses untuk menciptakan, mengkomunikasikan, dan menghantarkan nilai kepada pelanggan dan untuk mengelola hubungan 
JEMAP : Jurnal Ekonomi, Manajemen, Akuntansi dan Perpajakan

ISSN :

| Vol. 1 | No. 1 | April 2018

pelanggan dengan cara yang menguntungkan organisasi dan pemegang kepentingan (Kotler dan Keller, 2009).

\section{Periklanan}

Periklanan merupakan suatu bentuk komunikasi dengan cara berbayar dan termediasi dari sumber-sumber yang jelas, didesain untuk mempengaruhi konsumen yang lebih dari tindakan sebelumnya seperti meningkatkan kesadaran akan merk dan kesukaan mereka terhadap merk yang diiklankan (Shimp, 2014). The Institute of Practitioner in Advertising (IPA) (2010) memberikan 5 langkah dalam mengelola penyampaian pesan iklan yang baik : menetapkan tujuan iklan; menetapkan anggaran iklan; menentukan pesan kunci iklan; memutuskan media iklan yang dipergunakan; dan mengevaluasi hasil dari kampanye iklan.

\section{Fungsi-Fungsi Periklanan}

Menurut Shimp (2004) secara umum, periklanan dihargai karena dikenal sebagai pelaksana beragam fungsi komunikasi yang penting bagi perusahaan bisnis dan organisasi lainnya. Periklanan berfungsi 1) Informing (memberikan informasi). Periklanan membuat konsumen mengenal akan merek-merek suatu produk, serta mendidik mereka tentang fitur dan mengetahui manfaat produk, serta memfasilitasi penciptaan citra merek yang positif .2) Persuading (memberi pengaruh/membujuk). Iklan yang efektif akan mampu membujuk pelanggan untuk mencoba produk dan jasa yang diiklankan. 3) Reminding and the privilege show (mengingatkan dan memperlihatkan keistimewaan). Iklan menjaga agar merek perusahaan tetap segar dalam ingatan para konsumen. 4) Adding Value (menambah nilai). Ada 3 hal mendasar dimana perusahaan bisa memberikan nilai tambah bagi penawaranpenawaran mereka, antara lain: inovasi, penyempurnaan kualitas, atau mengubah persepsi konsumen. Ketiga komponen nilai tambah tersebut benar-benar independen. 5) Membantu upaya perusahaan. Peran lain dalam periklanan adalah membantu perwakilan penjualan. Iklan mengawali proses penjualan produkproduk perusahaan dan memberikan pendahuluan yang bernilai bagi 
JEMAP : Jurnal Ekonomi, Manajemen, Akuntansi dan Perpajakan

ISSN : $\quad$ Vol. 1 | No. 1 | April 2018

wiraniaga sebelum melakukan kontak personal dengan para pelanggan yang prospektif.

\section{Tujuan iklan}

Menurut Kennedy dan Soemanagara (dalam Satriojati, 2007) mengatakan bahwa tujuan dari iklan yaitu meningkatkan perubahan sikap dan perilaku konsumen. Strategi komunikasi yang dirancang secara tepat akan menghasilkan tindakan yang diinginkan. Berikut tujuan utama dari kegiatan periklanan: 1. Menyadarkan audiens serta member informasi mengenai sebuah barang, jasa atau ide.

2. Menumbuhkan dalam diri audiens suatu perasaan suka akan barang, jasa atau ide yang disajikan dengan memberinya persepsi.

3. Meyakinkan audiens akan kebenaran tentang apa yang dianjurkan dalam iklan dan karenanya menggerakkannya untuk berusaha memiliki atau menggunakan barang atau jasa yang dianjurkan.

\section{Periklanan Online}

Dalam dunia modern saat ini, hampir mustahil meraih penjualan kepada sebanyak mungkin orang dengan cara menawarkan barang dari pintu ke pintu, dikarenakan biaya operasi dan kegiatan seperti itu cenderung terlalu besar. Apalagi di jaman modern sekarang ini, dimana semua orang sudah menggunakan gadget dan selalu hidup dengan serba internet. Untuk jaman sekarang diperlukan pemasaran secara internet. Pemasaran internet juga disebut sebagai web marketing, online marketing atau e-marketing, atau $e$ commerce merupakan pemasaran dari produk atau jasa melalui internet (Rermawan, 2012: 206). Pemasaran melalui internet sebenarnya sederhana dalam makna namun kompleks dalam implementasinya. Dengan menggunakan internet pemasaran produk dapat bisa lebih terbantu, karena internet memungkinkan proses pemasaran yang lebih efektif, respons yang lebih cepat dan biaya yang lebih murah. Selain itu pemasar internet atau online yang berorientasi pada pasar sasaran dalam kenyataanya juga harus cermat dalam menyikapi konsumen. 
JEMAP : Jurnal Ekonomi, Manajemen, Akuntansi dan Perpajakan

ISSN : $\quad$ | Vol. 1 | No. 1 | April 2018

\section{Periklanan atau Pemasaran melalui Jejaring sosial}

Periklanan atau pemasaran melalui jejaring sosial terkait dengan pengguna sosial media yang dimiliki, sosial media yang dibayar, serta media sosial yang didasarkan pada aktivitas sebagai sumber pendapatan. Saat ini banyak dari anak muda hingga orang dewasa mempunyai dan menggunakan media sosial. Menyadari hal ini, banyak dari pengusaha besar seperti perusahaan dan pengusaha kecil menggunakan kesempatan ini untuk menarik konsumen, sekaligus untuk mendengarkan dan merespon konsumen potensial.

\section{Media Sosial}

Media sosial adalah teknologi yang mobile dan berbasis web, yang mendorong interaksi di antara pihak-pihak yang menggunakannya (Rermawan, 2012). Meskipun sosial media banyak ragamnya, tetapi Instagram, Facebook, dan Twitter merupakan beberapa jejaring sosial yang menonjol. Setiap media sosial memiliki karakteristik yang berbeda (Nisrina, 2015).

1. Instagram. Instagram disusun dari dua kata "insta" dan "gram". Yang berarti insta yang berasal dari kata instan karena bisa cepat dalam memperoleh foto. Sedangkan "gram" berasal dari kata "telegram" karena cara kerja telegram yang cepat dalam menyampaikan informasi kepada semua orang. Instagram sanggup mengunggah foto dengan cara memanfaatkan jaringan internet sehingga tiap informasi bisa dikirim dan diterima dengan sangat cepat. Sistem sosial pada Instagram ialah dengan menjadi pengikut akun pengguna lainnya, atau mempunyai pengikut Instagram. Maka dari itu kegiatan komunikasi antar pengguna Instagram bisa terjalin dengan memberikan tanda suka "love" dan juga memberi komentar pada foto yang sudah diunggah pengguna lainnya. Para pengikut (follower) merupakan salah satu elemen yang penting, karena jumlah tanda duka yang terkumpul dari follower sangat mempengaruhi populer atau tidaknya sebuah foto. Untuk mendapatkan teman dalam Instagram, pengguna dapat memanfaatkan teman-teman mereka 
JEMAP : Jurnal Ekonomi, Manajemen, Akuntansi dan Perpajakan

ISSN : $\quad$ Vol. 1 | No. 1 | April 2018

yang juga tergabung pada Instagram melalui beberapa jejaring sosial seperti Twitter dan Facebook. Dalam bermain Instagram, adanya hashtag memudahkan pengguna untuk mengelompokkan tema foto tertentu dan jika pengguna ingin mencari sebuah tema tertentu dengan cepat.

2. Facebook. Facebook adalah media sosial yang diluncurkan pada 4 Februari 2004, oleh Mark Zuckerberg, seorang lulusan Harvard University dan mantan murid Ardsley High School. Asal mula Facebook ini sebenarnya merupakan aplikasi yang dibuat Mark yang memiliki tujuan untuk berkomunikasi antara mahasiswa Harvard.

3. Twitter. Definisi dari twitter adalah media sosial yang digunakan dengan cara tweet (menyampaikan sebuah pesan) dengan maksimum sebanyak 140 karakter. Twitter didirikan pada bulan Maret 2006 oleh Jack Dorsey.

\section{Endorser}

Endorser adalah pendukung iklan atau juga yang dikenal sebagai bintang iklan yang mendukung produk iklan tertentu. Endorser terbagi dalam dua jenis yaitu Typical Person Endorser dan Celebrity Endorser. Pengertian dari Typical Person endorser adalah penggunaan beberapa orang yang tidak berasal dari kalangan selebritis untuk menyampaikan pesan mengenai sebuah produk. Celebrity Endorser adalah penggunaan orang yang telah terkenal yang dapat mempengaruhi orang lain karena prestasi yang dimilikinya (Shimp, 2004). Dari kedua jenis endorser diatas terdapat kesamaan dalam karakteristik dan atribut hanya saja dibedakan dalam jumlah penggunaan orang yang di dalamnya sebagai pendukung. Apakah yang digunakan sebagai endorser merupakan tokoh terkenal atau tidak.

Dalam penggunaanya dalam Instagram seorang yang berasal dari kaum selebritis diasumsikan lebih kredibel daripada orang yang tidak berasal dari kaum selebriti, entah itu dari segi penampilan fisik ataupun dari segi penampilan nonfisik. Selebriti dapat membuat sebuah iklan menjadi lebih menarik dan digemari oleh konsumen. Tingkat kepopuleran, citra, dan performa seorang selebriti itu sendiri dapat lebih menarik perhatian target market untuk menyaksikan iklan 
JEMAP : Jurnal Ekonomi, Manajemen, Akuntansi dan Perpajakan

yang dapat mempengaruhi presepsi target audien untuk membuat keputusan dalam melakukan pembelian (Cracken, 2006).

Celebrity Endorsement merupakan sebuah strategi komunikasi yang dilakukan oleh pemasar dalam membangun citra antara merek dengan konsumen. Celebrity Endorser diasumsikan mampu memberikan respon dan minat pembelian yang lebih positif dibandingkan dengan Typical person endorser. Hasil dari penelitian ini adalah penggunaan selebriti endorser sebagai pendukung sukses dalam menarik perhatian konsumen. Contohnya selebriti tersebut memiliki suatu program televisi yang disukai oleh konsumen maka selebriti itu bisa dipakai sebagai endorser yang dirasa cocok untuk mendukung perusahaan yang menghasilkan produk atau jasa tersebut.

Jenis celebrity endorser sendiri menurut (Shimp, 2004) dibagi menjadi tiga yaitu:

- Orang biasa, yaitu orang-orang yang tidak berasal dari kalangan selebriti yang disebut sebagai non-selebriti yang menggunakan atau mendukung suatu produk.

- Selebriti, yaitu merupakan tokoh (aktor, penghibur, atau atlit) yang dikenal masyarakat di dalam bidang-bidang yang berbeda.

- Para Ahli, yang merupakan orang-orang yang pendapatnya mengenai suatu produk tertentu dituruti oleh orang-orang yang kurang tahu tentang produk tersebut. Biasanya, mereka mempunyai peran yang penting dalalam komunikasi dari mulut ke mulut tentang suatu produk.

Berdasarkan ketiga jenis celebrity endorser di atas, endorser dalam penelitian ini adalah dari kalangan selebriti yang juga merupakan seorang ahli.

\section{E-commerce}

E-commerce merupakan lingkungan digital yang memungkinkan transaksi komersial terjadi di antara banyak organisasi dan individu (Laudon \& Laudon, 2007). Secara singkat, e-commerce merupakan transaksi secara online menggunakan internet. Ada banyak cara untuk mengklasifikasikan transaksi ECommerce. Salah satunya dengan melihat sifat peserta yang terlibat dalam transaksi e-Commerce. Berdasarkan sifat penggunanya, E-Commerce dibagi 
menjadi 3 jenis . E-Commerce $B$ to $C$, bisnis ke konsumen, melibatkan penjualan produk dan layanan secara eceran kepada pembeli perorangan. ECommerce $B$ to $B$, bisnis ke bisnis, melibatkan penjualan produk dan layanan antar perusahaan. E-Commerce $C$ to $C$, konsumen ke konsumen, melibatkan konsumen yang menjual secara langsung ke konsumen.

\section{Kerangka Pikir}

Terdapat 13 variabel yang akan dianalisa untuk menemukan alasan yang mendukung serta manfaat bagi pengusaha kuliner yang menggunakan jasa iklan instagram terhadap endorser "jakul semarang".

X1. Jumlah followers akun endorser

X2. Hashtag yang mudah dikenali (\#jajanankulinersemarang)

X3. Kredibilitas Endorser

X4. Kinerja endorser

X5. Pelayanan jasa yang ramah

X6. Harga jasa Promosi

X7. Daya tarik positif endorser

X8. Tampilan gambar produk

X9. Caption Endorser

X10. Efektivitas

X11. Kepercayaan terhadap jumlah followers dan likers

X12. Jumlah Liker di setiap gambar

X13. Pasar konsumennya tepat

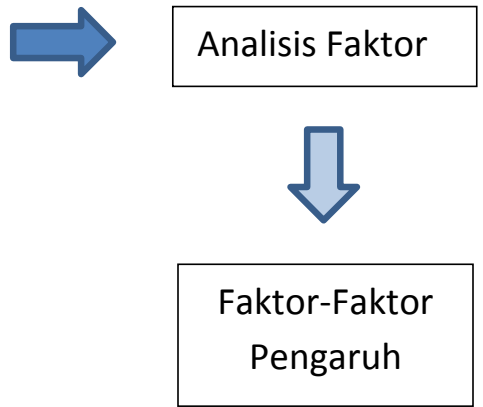

\section{Definisi Operasional V Gambar 1. Kerangka Pikir Penelitian}

- Jumlah followı Jwers akun endorser yang bisa menjadi pertimbangan para seller untuk melakukan promosi.

- Hashtag yang mudah dikenali (\#jajanankulinersemarang) adalah hashtag yang disampaikan oleh endorser, yang dapat membuat setiap gambar yang diupload dapat dilihat oleh semua orang yang terkait dengan hashtag tersebut.

- Kredibilitas Endorser adalah kredibilitas yang mengacu pada kecenderungan untuk percaya seseorang. Ketika sebuah sumber 
informasi, seperti endorser dianggap kredibel maka sikap penonton dapat berubah. Intinya kredibilitas adalah kepercayaan dan keahlian. Para endorser harus membuktikan bahwa mereka tdak berusaha untuk memanipulasi para penonton dan bahwa mereka objektif dengan presentasi mereka. Dengan demikian, para endorser dapat dinyatakan kredibel.

- Kinerja endorser adalah para pengusaha akan dapat mempercayai dan yakin jika sang endorser mudah diajak bekerja sama dengan baik, dapat mengatur waktu, tidak rumit.

- Pelayanan yang ramah adalah Pelayanan endorser yang ramah saat ingin menawarkan untuk menjadi endorser.

- Harga Jasa Promosi adalah harga jasa promosi termasuk faktor penting untuk para seller melakukan promosi online. Seperti halnya keputusan manajerial yang melibatkan beberapa alternatif, seorang brand manager harus mempertimbangkan biaya-manfaat untuk menentukan apakah biaya promosi yang lebih mahal dapat dibenarkan dalam hal pengembalian secara proporsional lebih besar pada investasi.

- Daya tarik positif endorser adalah Daya tarik merupakan atribut umum yang memberikan kontribusi untuk efektivitas endorser. sejumlah karakteristik positif yang dapat dilihat oleh konsumen dalam diri endorser seperti ketrapilan intelektual, sifat kepribadian, karakteristik gaya hidup, dan sebagainya.

- Tampilan gambar produk adalah tampilan gambar produk yang diupload oleh endorser, bisa dapat menarik para konsumen tergiur dan ingin membeli produk tersebut.

- Caption Endorser adalah Caption endorser pada setiap gambar harus jelas tentang produk apa yang dipromosikan dan bisa membujuk para konsumen untuk membeli atau pun menengok produk tersebut.

- Efektivitas endorser adalah Efektivitas yang dimaksud adalah adanya hasil dari melakukan promosi, dan memperoleh feedback. 
- Kepercayaan terhadap jumlah followers dan likers adalah dalam akun "Jakul Semarang" dapat diyakinkan adanya faktor kepercayaan di liker atau followers.

- JumIah Iikers di setiap gambar adalah dalam akun "Jakul Semarang" di setiap gambar memiliki banyak likers dari 900 hingga 1500 ke atas.

- Pasar konsumen yang tepat adalah "Jakul Semarang" memiliki follower yang merupakan calon pasar konsumen yang tepat bagi para pengusaha.

\section{METODE PENELITIAN}

\section{Populasi dan Sampling}

Obyek dalam penelitian ini adalah para pengusaha yang pernah melakukan promosi produk kuliner melalui "Jakul Semarang" endorser online shop di instagram. Populasi penelitian ini adalah pengusaha kuliner yang pernah melakukan promosi produk kuliner melalui endorser kuliner online "Jakul Semarang" di Instagram. Sampel merupakan bagian dari jumlah dan karakteristik yang dimiliki oleh populasi tersebut (Sugiyono, 2014: 149). Sampel dalam penelitian ini adalah pengusaha kuliner yang pernah melakukan promosi produk kuliner melalui endorser kuliner online "Jakul Semarang" di instagram. Digunakan metode non-probability sampling. Kriteria responden yang menjadi sampel adalah sebagai berikut: Pemilik usaha atau yang mewakili pemilik usaha; Pernah melakukan promosi produk kuliner secara online di akun "jakul semarang", pada 1 tahun ini (2015-2016). Untuk penelitian yang menggunakan analisis faktor maka sampel yang dianggap mewakili adalah jumlah variabel dikalikan 5. Variabel yang ditemukan terdapat 13, maka dikalikan 5 hasilnya 65. Dengan demikian responden dalam penelitian ini berjumlah 65 orang.

\section{Teknik Pengumpulan Data}

Dalam penelitian ini, data yang digunakan adalah data primer. Sumber data primer merupakan sumber data yang diperoleh peneliti secara langsung dari responden. Data primer dalam penelitian ini diperoleh dari jawaban 
responden yang telah mengisi kuesioner tentang alasan pengusaha kuliner menggunakan jasa iklan Instagram terhadap endorser "Jakul Semarang".

Suatu kuesioner dikatakan valid jika pertanyaan pada kuesioner mampu untuk mengungkapkan sesuatu yang akan diukur oleh kuesioner tersebut (Ghozali, 2001). Berikut adalah hasil uji validitas:

Tabel 1. Hasil Uji Validitas

\begin{tabular}{|c|c|c|c|}
\hline Variabel & r Hitung & r Tabel & Keterangan \\
\hline X1 & 0,386 & 0,2441 & Valid \\
\hline X2 & 0,611 & 0,2441 & Valid \\
\hline X3 & 0,557 & 0,2441 & Valid \\
\hline X4 & 0,588 & 0,2441 & Valid \\
\hline X5 & 0,457 & 0,2441 & Valid \\
\hline X6 & 0,414 & 0,2441 & Valid \\
\hline X7 & 0,347 & 0,2441 & Valid \\
\hline X8 & 0,336 & 0,2441 & Valid \\
\hline X9 & 0,417 & 0,2441 & Valid \\
\hline X10 & 0,394 & 0,2441 & Valid \\
\hline X11 & 0,525 & 0,2441 & Valid \\
\hline X12 & 0,323 & 0,2441 & Valid \\
\hline X13 & 0,417 & 0,2441 & Valid \\
\hline
\end{tabular}

Sumber: data primer yang diolah (2016)

Berdasarkan hasil uji validitas di atas, dengan ketentuan Df $=$ Jumlah Responden $-2(\mathrm{Df}=65-2=63)$ dan alpha 5\%, maka digunakan $\mathrm{r}$ Tabel $65=0,2441$. Keseluruhan variabel dalam penelitian ini dinyatakan valid.

Suatu kuesioner dikatakan reliabel atau handal jika jawaban seseorang terhadap pernyataan adalah konsisten atau stabil dari waktu ke waktu (Ghozali, 2001). Uji reliabilitas menggunakan SPSS versi 20 dengan menggunakan model Cronbach's Alpba ( $\alpha$ ). Jadi suatu kuesioner akan dikatakan reliabel apabila jawaban responden terhadap pertanyaan atau 
pernyataan konsisten dari waktu ke waktu. Variabel akan dikatakan reliabel apabila nilai Cronbach’s Alpha $>0,60$.

\section{Metode Analisis Data}

Dalam penelitian ini peneliti menggunakan 2 analisis, yaitu analisis deskriptif dan analisis faktor. Analisis statistik deskriptif adalah alat analisis yang digunakan untuk menganalisis data dengan melakukan deskripsi atau menggambarkan data- data yang telah terkumpul tanpa bermaksud untuk membuat kesimpulan yang berlaku untuk umum (Sugiyono, 2014). Guna mengukur variabel-variabel yang terdapat pada penelitian ini, digunakan metode kuesioner yang menggunakan skala likert. Skala Likert digunakan untuk mengukur sikap,pendapat,dan presepsi seseorang atau sekelompok orang tentang fenomena sosial. Skala Likert memiliki 5 skala jawaban dengan rentang skala. Kategori jawaban pada kuesioner dapat dilihat sebagai berikut: Skor 1 untuk Sangat Tidak Setuju (STS), Skor 2 untuk Tidak Setuju (TS); Skor 3 untuk Netral (N); Skor 4 untuk Setuju (S); dan Skor 5 untuk Sangat Setuju (SS). Sehingga, range skala untuk penelitian ini adalah:

Tabel 2. Rentang Skala dan Kategori

\begin{tabular}{|c|c|}
\hline Rentang Skala & Kategori \\
\hline $1,0-1,8$ & Sangat Tidak Setuju \\
$1,8-2,6$ & Tidak Setuju \\
$2,6-3,4$ & Netral Setuju \\
$3,4-4,2$ & Setuju \\
$4,2-5,0$ & Sangat Setuju \\
\hline
\end{tabular}

Analisis faktor adalah analisis yang mempunyai prinsip untuk meringkas data informasi menjadi lebih sedikit dan menamakanya sebagai faktor. Analisis ini mempunyai tujuan untuk menyelesaikan permasalahan di dalam menganalisis hubungan antara beberapa variabel dan meringkas variabel variabel tersebut ke dalam bentuk variabel baru yaitu faktor (Santoso \& Tjiptono, 2001: 248). 
Proses - proses analisis faktor adalah sebagai berikut :

1. Memilih variabel yang layak dimasukkan ke dalam analisis faktor.

2. Melakukan ekstraksi variabel hingga menjadi satu atau beberapa faktorfaktor.

3. Proses Rotasi Faktor.

4. Menamakan faktor-faktor yang sudah terbentuk.

5. Menentukan faktor dominan.

\section{HASIL DAN PEMBAHASAN}

\section{Deskripsi Responden}

Responden dengan usia 24-29 tahun adalah kategori usia yang paling terbanyak dalam penelitian ini. Dimana usia ini merupakan usia muda yang merupakan pemain online utama di Jakul Semarang. Jenis kelamin responden sebagian besar 36 responden atau 55,4\% berjenis kelamin pria dan sisanya 29 responden atau 44,6\% berjenis kelamin wanita. Produk yang dipromosikan sebagian besar produk makanan.

Berikut adalah tabel tabulasi silang identitas responden yang menunjukkan data rentang frekuensi promosi dengan waktu terakhir kali responden melakukan promosi di Jakul Semarang:

Tabel 3. Frekuensi Promosi dan Promosi Terakhir Responden

\begin{tabular}{|c|c|c|c|c|c|c|c|}
\hline \multirow[b]{2}{*}{$\begin{array}{c}\text { Frekuensi } \\
\text { promosi }\end{array}$} & \multicolumn{5}{|c|}{ Promosi Terakhir Responden } & \multirow[b]{2}{*}{ TOTAL } & \multirow[b]{2}{*}{$\%$} \\
\hline & $\begin{array}{c}1- \\
2 \\
\text { bulan } \\
\text { yang } \\
\text { lalu }\end{array}$ & $\begin{array}{c}2-3 \\
\text { bulan } \\
\text { yang } \\
\text { lalu }\end{array}$ & $\begin{array}{c}3-4 \\
\text { bulan } \\
\text { yang } \\
\text { lalu }\end{array}$ & $\begin{array}{c}4-5 \\
\text { bulan } \\
\text { yang } \\
\text { lalu }\end{array}$ & $\begin{array}{c}\text { Diatas } 5 \\
\text { bulan } \\
\text { yang } \\
\text { lalu }\end{array}$ & & \\
\hline 1-2 kali & 13 & 4 & 6 & 2 & 19 & 44 & 67.7 \\
\hline 3-4 kali & 5 & 4 & 3 & 1 & 5 & 18 & 27.7 \\
\hline $5-6$ kali & $\mathrm{O}$ & $\mathrm{O}$ & o & $\mathrm{O}$ & $\mathrm{O}$ & $\mathrm{O}$ & - \\
\hline $\begin{array}{c}\text { Diatas } 6 \\
\text { kali }\end{array}$ & 1 & $\mathrm{O}$ & o & $\mathrm{o}$ & 2 & 3 & 4.6 \\
\hline $\begin{array}{c}\text { TOTAL } \\
(\%)\end{array}$ & $\begin{array}{c}19 \\
(29,2 \%)\end{array}$ & $\begin{array}{c}8 \\
(12,3 \%)\end{array}$ & $\begin{array}{c}9 \\
(13,8 \%)\end{array}$ & $\begin{array}{c}3 \\
(4,6 \%)\end{array}$ & $\begin{array}{c}26 \\
(40,0 \%)\end{array}$ & 65 & 100 \\
\hline
\end{tabular}

Sumber: Data primer yang diolah (2016) 
Dari tabel tabulasi silang di atas, dapat diketahui bahwa dari 65 responden yang pernah melakukan promosi di Jakul Semarang melalui Instagram, 19 orang yang paling banyak melakukan promosi 1-2 kali dan dalam rentan waktu diatas 5 bulan yang lalu. Maka dari itu sebaiknya Jakul Semarang lebih mendorong para pengusaha untuk melakukan promosi ulang di Jakul Semarang.

\section{Akun Foodstagram selain Jakul Semarang}

Berikut adalah tabel identitas akun foodstagram yang pernah diikuti oleh para responden selain Jakul Semarang:

Tabel 4. Akun Endorser Foodstagram Selain Jakul Semarang

\begin{tabular}{|l|c|c|}
\hline \multicolumn{1}{|c|}{ Keterangan } & Jumlah & Persentase (\%) \\
\hline akucintamakansemaranglacms & 26 & 36,1 \\
\hline Semarangfoodstagram & 6 & 8,3 \\
\hline kuliner.semarang & 7 & 9,7 \\
\hline Makandisemarang & 2 & 2,8 \\
\hline Smgfoodhunter & 8 & 11,1 \\
\hline Makanansemarang & 1 & 1,4 \\
\hline belum pernah & 22 & 30,6 \\
\hline Total & $\mathbf{7 2}$ & $\mathbf{1 0 0}$ \\
\hline
\end{tabular}

Sumber: Data primer yang diolah (2016)

Dari tabel di atas, dapat diketahui bahwa akun endorser foodstagram yang paling dominan dipilih oleh responden yang pernah melakukan promosi selain di akun jakul adalah akun instagram akucintamakanansemarang(ACMS) dengan perolehan persentase sebesar 36,1\% dari total jawaban. Sedangkan untuk yang belum pernah melakukan promosi di tempat lain sebanyak 30.6\%. Sehingga ACMS yang merupakan jasa endorser foodstagram bisa menjadi pesaing utama untuk Jakul Semarang, dan Jakul Semarang harus berupaya keras untuk memberikan kepercayaan yang lebih kepada para pengusaha agar para pengusaha tetap selalu berpromosi di Jakul Semarang. 


\section{Alasan memilih Jakul Semarang}

Berikut adalah tabel identitas responden tentang alasan para responden memilih Jakul Semarang sebagai media promosi online untuk produk mereka:

\section{Tabel 5. Alasan Memilih Jakul Semarang Sebagai Endorser}

\begin{tabular}{|l|c|c|}
\hline Keterangan & Jumlah & Persentase (\%) \\
\hline Followers banyak & 37 & 34,9 \\
\hline $\begin{array}{l}\text { Pasar konsumen yang luas dan } \\
\text { Tepat }\end{array}$ & 7 & 6,6 \\
\hline Akun endorser dapat di percaya & 10 & 9,4 \\
\hline Produk lebih dikenal di masyarakat & 5 & 4,7 \\
\hline likers banyak dan nyata & 8 & 7,5 \\
\hline $\begin{array}{l}\text { Terdapat banyak comment di setiap } \\
\text { Gambar }\end{array}$ & 3 & 2,8 \\
\hline Tampilan gambar produk menarik & 12 & 11,3 \\
\hline $\begin{array}{l}\text { Cepatnya kinerja endorser dalam } \\
\text { Mempromosikan }\end{array}$ & 3 & 0,9 \\
\hline Harga Promosi terjangkaulmurah & 6 & 5,7 \\
\hline Followers benar-benar adal aktif & 3 & 2,8 \\
\hline $\begin{array}{l}\text { Memiliki daya tarik untuk menarik } \\
\text { customer baru }\end{array}$ & 3 & 2,8 \\
\hline $\begin{array}{l}\text { Review menurut para pengusaha Jakul } \\
\text { Semarang bagus untuk mempromosikan }\end{array}$ & $\mathbf{1 0 6}$ & 1,9 \\
\hline $\begin{array}{l}\text { Akun endorser diketahui banyak } \\
\text { Masyarakat }\end{array}$ & 2,7 \\
\hline $\begin{array}{l}\text { Termasuk akun top kuliner } \\
\text { Semarang }\end{array}$ & 3 & $\mathbf{1 0 0}$ \\
\hline Total & 3 & \\
\hline
\end{tabular}

Sumber: Data primer yang diolah (2016)

Dari tabel di atas, dapat diketahui dari jawaban yang diberikan oleh 65 responden terdapat $34,9 \%$ atau 37 orang menjelaskan alasan mereka memilih Jakul Semarang sebagai media promosi untuk produk mereka dikarenakan Jakul 
Semarang memiliki Followers yang banyak, sehinnga Jakul Semarang perlu mempertahankan agar followers nya terus meningkat.

Tabel berikut berisi total skor dan rata-rata skor jawaban dari 65 responden terhadap 13 variabel yang ada dalam penelitian ini:

Tabel 6. Tanggapan Responden

\begin{tabular}{|c|c|c|c|c|c|c|c|c|}
\hline \multirow[b]{2}{*}{ No } & \multirow[b]{2}{*}{ Variabel } & \multicolumn{5}{|c|}{ Frekuensi Jawaban (Skor) } & \multirow{2}{*}{$\begin{array}{l}\text { Rata } \\
\text {-rata }\end{array}$} & \multirow[b]{2}{*}{ Ket } \\
\hline & & STS & TS & $\mathbf{N}$ & $\mathrm{S}$ & SS & & \\
\hline 1 & $\begin{array}{c}\text { Jumlah Followers akun } \\
\text { endorser }\end{array}$ & $\begin{array}{c}0 \\
(0)\end{array}$ & $\begin{array}{c}6 \\
(12)\end{array}$ & $\begin{array}{c}0 \\
(0)\end{array}$ & $\begin{array}{c}33 \\
(132)\end{array}$ & $\begin{array}{c}26 \\
(130)\end{array}$ & 4,22 & Setuju \\
\hline 2 & $\begin{array}{l}\text { Hashtag yang mudah dikenali } \\
\text { (\#jajanankulinersemarang) }\end{array}$ & $\begin{array}{c}0 \\
(0)\end{array}$ & $\begin{array}{c}7 \\
(14)\end{array}$ & $\begin{array}{c}0 \\
(0)\end{array}$ & $\begin{array}{c}40 \\
(160)\end{array}$ & $\begin{array}{c}18 \\
(90)\end{array}$ & 4,06 & Setuju \\
\hline 3 & Kredibilitas endorser & $\begin{array}{c}0 \\
(0)\end{array}$ & $\begin{array}{c}0 \\
(0)\end{array}$ & $\begin{array}{c}0 \\
(0)\end{array}$ & $\begin{array}{c}43 \\
(172)\end{array}$ & $\begin{array}{c}22 \\
(110)\end{array}$ & 4,34 & Setuju \\
\hline 4 & Kinerja endorser & $\begin{array}{c}0 \\
(0)\end{array}$ & $\begin{array}{r}7 \\
(14) \\
\end{array}$ & $\begin{array}{c}0 \\
(0)\end{array}$ & $\begin{array}{c}44 \\
(176) \\
\end{array}$ & $\begin{array}{c}14 \\
(70)\end{array}$ & 4 & Setuju \\
\hline 5 & Pelayanan jasa yang amah & $\begin{array}{c}0 \\
(0)\end{array}$ & $\begin{array}{c}2 \\
(4)\end{array}$ & $\begin{array}{c}0 \\
(0)\end{array}$ & $\begin{array}{c}52 \\
(208)\end{array}$ & $\begin{array}{c}11 \\
(55)\end{array}$ & 4,11 & Setuju \\
\hline 6 & Rarga jasa promosi & $\begin{array}{c}0 \\
(0)\end{array}$ & $\begin{array}{c}6 \\
(12)\end{array}$ & $\begin{array}{c}0 \\
(0)\end{array}$ & $\begin{array}{c}45 \\
(180)\end{array}$ & $\begin{array}{c}14 \\
(70)\end{array}$ & 4,03 & Setuju \\
\hline 7 & Daya tarik positif endorser & $\begin{array}{c}0 \\
(0)\end{array}$ & $\begin{array}{c}17 \\
(34)\end{array}$ & $\begin{array}{c}0 \\
(0)\end{array}$ & $\begin{array}{c}48 \\
(192)\end{array}$ & $\begin{array}{c}0 \\
(0)\end{array}$ & 4,26 & Setuju \\
\hline 8 & Tampilan gambar produk & $\begin{array}{c}0 \\
(0)\end{array}$ & $\begin{array}{c}3 \\
(6)\end{array}$ & $\begin{array}{c}0 \\
(0)\end{array}$ & $\begin{array}{c}46 \\
(184)\end{array}$ & $\begin{array}{c}16 \\
(80)\end{array}$ & 4,15 & Setuju \\
\hline 9 & Caption Endorser & $\begin{array}{c}0 \\
(0) \\
\end{array}$ & $\begin{array}{c}8 \\
(16) \\
\end{array}$ & $\begin{array}{c}0 \\
(0) \\
\end{array}$ & $\begin{array}{c}43 \\
(172) \\
\end{array}$ & $\begin{array}{c}14 \\
(70)\end{array}$ & 3,97 & Setuju \\
\hline 10 & Efektivitas & $\begin{array}{c}0 \\
(0)\end{array}$ & $\begin{array}{c}2 \\
(4)\end{array}$ & $\begin{array}{c}0 \\
(0)\end{array}$ & $\begin{array}{c}35 \\
(140)\end{array}$ & $\begin{array}{c}28 \\
(140)\end{array}$ & 4,37 & Setuju \\
\hline 11 & $\begin{array}{l}\text { Kepercayaan terhadap jumlah } \\
\text { followers dan likers }\end{array}$ & $\begin{array}{c}0 \\
(0)\end{array}$ & $\begin{array}{c}0 \\
(0)\end{array}$ & $\begin{array}{c}0 \\
(0)\end{array}$ & $\begin{array}{c}39 \\
(156)\end{array}$ & $\begin{array}{r}26 \\
(130)\end{array}$ & 4,4 & Setuju \\
\hline 12 & $\begin{array}{c}\text { Jumlah likers di setiap } \\
\text { Gambar }\end{array}$ & $\begin{array}{c}0 \\
(0)\end{array}$ & $\begin{array}{c}0 \\
(0)\end{array}$ & $\begin{array}{c}0 \\
(0)\end{array}$ & $\begin{array}{c}44 \\
(176)\end{array}$ & $\begin{array}{c}21 \\
(105)\end{array}$ & 4,32 & Setuju \\
\hline 13 & $\begin{array}{c}\text { Pasar konsumennya } \\
\text { Tepat }\end{array}$ & $\begin{array}{c}0 \\
(0)\end{array}$ & $\begin{array}{c}0 \\
(0)\end{array}$ & $\begin{array}{c}0 \\
(0)\end{array}$ & $\begin{array}{c}42 \\
(168)\end{array}$ & $\begin{array}{c}23 \\
(115)\end{array}$ & 4,35 & Setuju \\
\hline
\end{tabular}

Sumber: Data primer yang diolah (2016) 
Berdasarkan tabel di atas, tanggapan responden terhadap variabelvariabel yang ada di dalam penelitian ini adalah setuju.

\section{Analisis Faktor}

\section{KMO and Bartlett's Test}

Hasil yang diperoleh dari KMO and Bartlett's Test menggunakan program SPSS didapat KMO MSA sebesar 0,626 dan signifikan.

Tabe1 7. Hasi1 KMO and Bartlett's Test

\begin{tabular}{|c|c|c|}
\hline \multicolumn{2}{|c|}{$\begin{array}{c}\text { Kaiser-Meyer-Olkin } \\
\text { Adequacy }\end{array}$} & 0.626 \\
\hline \multirow{3}{*}{$\begin{array}{c}\text { Bartlett's Test } \\
\text { of Sphericity }\end{array}$} & Aprrox. Chi-Square & 133.689 \\
\cline { 2 - 3 } & Df & 66 \\
\cline { 2 - 3 } & sig. & 0.000 \\
\hline
\end{tabular}

Sumber: Data primer yang diolah (2016)

\section{Total Variance Explained}

Uji ini dilakukan untuk menentukan jumlah faktor terbentuk yang paling optimal. Berikut adalah hasil pengolahannya dengan menggunakan SPSS.

Tabel 8. Total Variance Explained

\begin{tabular}{|c|c|c|c|r|r|r|}
\hline \multirow{2}{*}{ Component } & \multicolumn{3}{|c|}{ Initial Eigenvalues } & \multicolumn{3}{|c|}{$\begin{array}{c}\text { Extraction Sums of } \\
\text { Squared }\end{array}$} \\
\cline { 2 - 7 } & Total & $\begin{array}{c}\text { \% of } \\
\text { Variance }\end{array}$ & $\begin{array}{c}\text { Cumulative } \\
\text { \% }\end{array}$ & Total & $\begin{array}{c}\text { \% of } \\
\text { Variance }\end{array}$ & $\begin{array}{c}\text { Cumulative } \\
\text { \% }\end{array}$ \\
\hline 1 & 2.809 & 23.405 & 23.405 & 2.809 & 23.405 & 23.405 \\
\hline 2 & 1.477 & 12.312 & 35.717 & 1.477 & 12.312 & 35.717 \\
\hline 3 & 1.354 & 11.287 & 47.004 & 1.354 & 11.287 & 47.004 \\
\hline 4 & 1.177 & 9.805 & 56.809 & 1.177 & 9.805 & 56.809 \\
\hline 5 & .992 & 8.264 & 65.073 & & & \\
\hline 6 & .934 & 7.784 & 72.857 & & & \\
\hline 7 & .828 & 6.896 & 79.753 & & & \\
\hline 8 & .672 & 5.597 & 85.350 & & & \\
\hline 9 & .583 & 4.858 & 90.208 & & & \\
\hline 1 & .508 & 4.232 & 94.440 & & & \\
\hline 1 & .420 & 3.503 & 97.943 & & & \\
\hline 1 & .247 & 2.057 & 100.000 & & & \\
\hline & & & & & & \\
\hline
\end{tabular}

Sumber: Data primer yang diolah(2016) 
Dari tabel di atas, dapat dilihat bahwa terdapat 4 (empat) faktor yang terbentuk. Jumlah ini dianggap paling optimal karena memiliki angka eigenvalues di atas 1,00 .

\section{Rotated Component Matrix}

Berikut adalah hasil dari langkah rotasi faktor yang dilakukan menggunakan SPSS:

Tabe1 9. Rotated Component Matrix

\begin{tabular}{|l|c|c|c|c|}
\hline \multirow{2}{*}{ Variabel } & \multicolumn{4}{|c|}{ Component } \\
\cline { 2 - 5 } & 1 & 2 & 3 & 4 \\
\hline $\begin{array}{l}\text { Jumlah followers akun } \\
\text { Endorser }\end{array}$ & -.045 & .000 & .726 & .239 \\
\hline $\begin{array}{l}\text { Hashtag yang mudah } \\
\text { Dikenali }\end{array}$ & $\mathbf{5 6 6}$ & .126 & .396 & .156 \\
\hline Kredibilitas endorser & .354 & .383 & .257 & .338 \\
\hline Kinerja endorser & $\mathbf{. 5 3 1}$ & .366 & .000 & .082 \\
\hline $\begin{array}{l}\text { Pelayanan jasa yang } \\
\text { Ramah }\end{array}$ & .032 & $\mathbf{. 7 0 0}$ & .036 & .112 \\
\hline Rarga jasa promosi & .261 & $\mathbf{. 6 4 5}$ & -.150 & -.273 \\
\hline $\begin{array}{l}\text { Daya tarik positif } \\
\text { Endorser }\end{array}$ & -.070 & $\mathbf{. 6 5 3}$ & .161 & .134 \\
\hline $\begin{array}{l}\text { Tampilan gambar } \\
\text { Produk }\end{array}$ & .095 & .107 & .705 & -.209 \\
\hline Caption endorser & .126 & .221 & -.307 & $\mathbf{. 6 5 1}$ \\
\hline Efektivitas & .057 & -.036 & .212 & .772 \\
\hline $\begin{array}{l}\text { Kepercayaan terhadap } \\
\text { jumlah followers dan } \\
\text { likers }\end{array}$ & $\mathbf{. 8 7 2}$ & -.105 & .012 & .049 \\
\hline $\begin{array}{l}\text { Jumlah liker di setiap } \\
\text { Gambar }\end{array}$ & $\mathbf{. 8 4 0}$ & .045 & -.068 & .002 \\
\hline
\end{tabular}

Sumber: Data primer yang diolah (2016)

Seperti yang ditunjukkan dalam tabel, perbedaan antar variabel sudah terlihat jelas sehingga kemudian pengelompokkan variabel-variabel ke dalam faktor dapat dilakukan.

\section{Penamaan Faktor}

Setelah keempat faktor terbentuk, langkah berikutnya adalah dengan memberi nama masing-masing faktor tersebut, seperti yang dijelaskan dalam tabel berikut: 
Tabe1 10. Penamaan Faktor

\begin{tabular}{|c|c|c|c|c|}
\hline Variabe1 & $\begin{array}{c}\text { Factor } \\
\text { Loadings }\end{array}$ & $\begin{array}{c}\text { Variance } \\
(\%)\end{array}$ & Component & Nama Faktor \\
\hline $\begin{array}{l}\text { Kepercayaan terhadap } \\
\text { jumlah followers dan likers } \\
\text { (X11) }\end{array}$ & 0,872 & \multirow{4}{*}{23.405} & \multirow{4}{*}{ Faktor 1} & \multirow{4}{*}{$\begin{array}{l}\text { Faktor } \\
\text { kredibilitas } \\
\text { akun endorser }\end{array}$} \\
\hline $\begin{array}{l}\text { Jumlah likers di setiap } \\
\text { gambar }(\mathrm{X} 12)\end{array}$ & 0,840 & & & \\
\hline $\begin{array}{l}\text { Hashtag yang mudah } \\
\text { dikenali } \\
\text { (\#jajanankulinersemarang) (X2) }\end{array}$ & 0,566 & & & \\
\hline kinerja endorser (X4) & 0,531 & & & \\
\hline $\begin{array}{l}\text { Pelayanan jasa yang ramah } \\
\text { (X5) }\end{array}$ & 0,700 & \multirow{3}{*}{12.312} & \multirow{3}{*}{ Faktor 2} & \multirow{3}{*}{$\begin{array}{l}\text { Faktor } \\
\text { karakteristik } \\
\text { endorser }\end{array}$} \\
\hline Rarga jasa promosi (X6) & 0,645 & & & \\
\hline $\begin{array}{l}\text { Daya tarik positif endorser } \\
\text { (X7) }\end{array}$ & 0,653 & & & \\
\hline $\begin{array}{l}\text { Jumlah followers akun } \\
\text { endorser }(\mathrm{X} 1)\end{array}$ & 0,726 & \multirow{2}{*}{11.287} & \multirow{2}{*}{ Faktor 3} & \multirow{2}{*}{$\begin{array}{l}\text { Faktor gambar } \\
\text { produk yang } \\
\text { disukai } \\
\text { follower }\end{array}$} \\
\hline $\begin{array}{l}\text { Tampilan gambar produk } \\
\text { (X8) }\end{array}$ & 0,705 & & & \\
\hline Caption endorser (X9) & 0,651 & \multirow{2}{*}{9805} & \multirow{2}{*}{ Faktor 4} & \multirow{2}{*}{$\begin{array}{l}\text { Faktor } \\
\text { efektivitas } \\
\text { endorser }\end{array}$} \\
\hline Efektivitas (X10) & 0,772 & & & \\
\hline
\end{tabular}

Sumber: Data primer yang diolah (2016)

Berdasarkan tabel, berikut adalah penjelasan dari keempat faktor yang telah terbentuk:

1) faktor pertama dinamakan faktor kredibilitas akun endorser dengan nilai persentase varians sebesar 23,405\%. Faktor kredibilitas akun endorser mencakup 4 (empat) variabel, yaitu variabel kepercayaan terhadap jumlah followers dan likers, jumlah likers di setiap gambar, lalu variabel hashtag yang mudah dikenali (\#jajanankulinersemarang), faktor kinerja endorser, pelayanan jasa yang ramah. 
2) Faktor kedua dinamakan faktor karakteristik endorser, dengan nilai persentase varians sebesar $12,312 \%$, pemberian nama untuk faktor kedua dilihat berdasarkan variabel pelayanan jasa yang ramah, harga jasa promosi, daya tarik positif endorser.

3) Faktor ketiga dinamakan faktor gambar produk yang disukai follower. Faktor ini berisikan 2 variabel yaitu variable jumlah followers akun endorser, tampilan gambar produk di akun "Jakul Semarang". Faktor ini memiliki nilai persentase varians sebesar $11,287 \%$.

4) Faktor keempat adalah faktor sebab efektivitas endorser, dengan nilai persentase varians sebesar 9,805\%. Penamaan faktor ini berdasarkan 2 variabel yaitu variabel caption endorser dan variabel efektivitas.

\section{Implikasi Manajerial}

Beberapa hal yang dapat dijadikan arahan kebijakan bagi akun endorser kuliner Jakul Semarang adalah sebagai berikut:

1. Akun endorsen Jakul Semarang perlu mempergunakan hashtag yang lebih bervariasi, menarik dan yang sedang menjadi tren hashtag saat ini namun tidak meninggalkan karakterisitik dari Jakul Semarang.

2. Jakul Semarang perlu menciptakan hubungan yang lebih baik antara endorser dengan klien dengan cara melayani setiap permintaan dan pertanyaan klien dengan sikap yang ramah, sopan dan selalu memberikan jawaban yang tepat. Serta menciptakan potongan harga tertentu setelah klien sudah pernah beberapa kali berpromosi.

3. Akun endorser Jakul Semarang hendaknya lebih kreatif dengan menampilkan ide yang segar dan tidak biasa dalam mengemas tampilan gambar produk kuliner milik kliennya, dan menjaring para pengguna instagram berasal dari dalam kota semarang ataupun luar kota semarang untuk menjadi followers.

4. Pada soal caption, pengelola Jakul Semarang perlu membuat sebuaah caption yang lebih baik dengan menyusun isi caption secara terperinci dan tepat sesuai dengan harapan klien namun juga tetap terasa menarik dan mudah untuk disimak. 
JEMAP : Jurnal Ekonomi, Manajemen, Akuntansi dan Perpajakan

ISSN : $\quad$ | Vol. 1 | No. 1 | April 2018

\section{PENUTUP}

\section{Kesimpulan}

Berdasarkan hasil penelitian yang dilakukan, ditemukan bahwa sebagian besar pengusaha melakukan promosi secara online di Instagram melalui Jakul Semarang adalah berusia 24-29 tahun dan mayoritas berjenis kelamin pria. Para pengusaha melakukan promosi produknya secara online di Instagram melalui Jakul Semarang mayoritas adalah produk makanan utama. Promosi terakhir yang dilakukan para pengusaha sekitar diatas 5 bulan yang lalu, lalu untuk frekuensi promosi yang dilakukan oleh para pengusaha sebagian besar, 1-2 kali setiap promosi. Selanjutnya untuk efektivitas, sebagian besar para pengusaha yang telah melakukan promosi online di Jakul Semarang merasakan adanya efektivitas yang baik setelah promo di Jakul Semarang.

Analisis faktor yang telah dilakukan dalam penelitian ini telah merangkum 13 variabel menjadi 4 faktor, sehingga jumlah variabel berkurang menjadi 11 variabel (sisanya gugur). Dan berikut adalah faktor-faktor yang mendukung para pengusaha ingin mempromosikan produknya melalui endorser Instagram di Jakul Semarang: Faktor pertama adalah faktor kredibilitas akun endorser, dengan nilai persentase varians sebesar $23,405 \%$ dari nilai eigenvalues sebesar 2,809. Faktor kedua adalah faktor karakteristik endorser, dengan nilai persentase varians sebesar 12,312\% dari nilai eigenvalues sebesar 1,477. Faktor ketiga adalah faktor gambar produk yang disukai follower, dengan nilai persentase varians sebesar $11,287 \%$ dari nilai eigenvalues sebesar 1,354. Faktor keempat adalah efektivitas endorser, dengan nilai persentase varians sebesar 9,805\% dari nilai eigenvalues sebesar 1,177.

Dari hasil penelitian ini, dapat dilihat bahwa faktor kredibilitas akun endorser menjadi faktor yang paling dominan dalam mendorong para pengusahadi kota Semarang untuk melakukan promosi di Jakul Semarang, dengan nilai persentase varians sebesar 23,405\% dari eigenvalues sebesar 2,809. Faktor tersebut terdiri dari 4 (empat) variabel, yaitu variabel kepercayaan terhadap jumlah followers dan likers (X11), lalu variabel hashtag yang mudah 
dikenali (X2), variabel kinerja endorser (X4), dan variable jumlah liker di setiap gambar (X12).

\section{Saran}

Saran menurut hasil yang didapat dalam penelitian ini mempertahankan kredibilitas akun endorser, yang berkaitan dengan variabel kepercayaan terhadap jumlah followers dan likers, lalu variabel hashtag yang mudah dikenali, variabel kinerja endorser, dan variabel jumlah liker di setiap gambar. Para pengusaha terdorong untuk melakukan promosi di Jakul Semarang karena percaya jumlah follower dan likers yang banyak. Di akun mereka dapat pengecekan followers yang terjaga keasliannya serta mempersingkat sistem kerja yang kurang efektif pada Jakul Semarang.

Selain itu Jakul Semarang perlu menambah hashtag yang lebih bervariasi dan banyak digunakan dan dicari oleh para follower (calon konsumen) seperti \#jajanansemarang, dan \#semarangculinary karena dengan begitu promosi "Jakul Semarang" menjadi lebih luas oleh para calon konsumen atau para pengguna Instagram.

Lalu untuk kinerja endorser, endorser harus dapat mudah bekerja sama dan cepat tanggap dengan pekerjaan nya sebagai jasa endorser foodstagram dengan pengusah kuliner, supaya bersedia lansung untuk mngendorse langsung di tempat, seperti cafe atau restoran.

Yang terakhir adalah jumlah liker di setiap gambar, dalam penelitian ini para pengusaha yang melakukan promosi di Jakul Semarang percaya dengan akun Jakul Semarang dikarenakan terdapatnya likers yang berjumlah banyak disetiap gambar, sehingga Jakul Semarang sebaiknya bisa memberi tambahan liker di setiap gambar dengan bertambahnya jumlah follower yang nyata. 


\section{DAFTAR PUSTAKA}

Alma, R. Buchari. 2004. Manajemen pemasaran dan pemasaran jasa. B andung: ALFABETA.

Badan Pusat Statistik. 2015. Pertumbuhan Produksi Industri Manufaktur Mikro Dan Kecil. Agustus. BPS Jawa Tengah. Semarang.

Ghozali, I. (2001). Aplikasi Analisis Multivariate Dengan Program IBM SPSS 19. Semarang: Badan Penerbit Universitas Diponegoro.

Rermawan, A. (2012). Komunikasi Pemasaran. Jakarta: Penerbit Erlangga.

Jajak Pendapat. (2016). \#INSTAFOOD Food Buyer On Instagram. Dikutip dari https:1lblog.jakpat.netlinstafood-food-buyer-on-instagraml

Kementerian Perindustrian RI. 2015. Menperin: Triwulan I tahun 2015, Industri Makanan dan Minuman Capai 8,16\%. Kepala Pusat Komunikasi Publik. Jakarta.

Kotler, P \& Amstrong, G. (2008). Prinsip-prinsip pemasaran 1. (12th ed). Jakarta: Erlangga.

Kotler, P. \& Keller, K. L. (2009). Manajemen Pemasaran, Edisi Ketiga Belas. Jakarta: Penerbit Erlangga.

Majalah Marketing Edisi 081XIVlAgustus12014, WSJ, Event Veritrans: Rise of E- Commerce

Nisrina. (2015). Bisnis Online: Manfaat Media Sosial Dalam Meraup Uang. Yogyakarta: Kobis.

Pangerapan, S. A. (2015). Pengguna Internet Indonesia Tahun 2014. Jakarta: Asosiasi Penyelenggara Jasa Internet Indonesia.

Shimp, Terence A. 2004. Periklanan Promosi Aspek Tambahan Komunikasi Pemasaran Terpadu. Jakarta: Erlangga.

Shimp, Terence A. 2014. Komunikasi Pemasaran Terpadu dalam Periklanan dan Promosi. Jakarta: Salemba Empat.

Satriojati, Wahyu Aji Anindhiyo. 2007. Analisis Perbandingan Efektifitas Iklan Animasi dan Non Animasi: Studi Produk Low-Involvement dan RighInvolvement. Jakarta: Universitas Indonesia. Skripsi.

Santoso, S. \& Tjiptono, F. 2001. Riset Pemasaran: Konsep dan Aplikasi dengan SPSS. Jakarta: PT Elex Media Komputindo.

Sugiyono. (2014). Metode Penelitian Kuantitatif Kualitatif dan R\&D. Bandung: Alfabeta. 